\title{
La Descosificación de los animales (I)
}

Keywords: descosificación de los animales, Código civil, seres sintientes, cosas en propiedad, no-cosas, estatuto jurídico de los animales.

Los animales han jugado un papel de gran importancia dentro de la sociedad, el derecho y la economía a lo largo de toda nuestra trayectoria histórica. A pesar de que se haya olvidado muchas veces el universal respeto por los animales, que es característico del Mundo Antiguo y que transmite el jurista Ulpiano, en el famoso texto del Digesto D. 1,1,1,3 ${ }^{1}$, en el que refiere la existencia y aplicación de un derecho propio de la naturaleza que es común a todos los seres vivos (sin distinción de si se trata de humanos o animales), toda nuestra cultura está impregnada por un profundo conocimiento y persuasión colectiva de que los animales son criaturas que comparten nuestro destino, lo que de modo sintético y eficaz proclama la expresión alemana "Mitgeschöpfte", para referirse a los animales ${ }^{2}$. Esta posición, remite fundamentalmente al respeto y veneración del hombre por la naturaleza que, en nuestro mundo occidental ${ }^{3}$, se ha ido desdibujando con el paso de los siglos, pero que es el que nos ha transmitido toda la literatura clásica greco-romana ${ }^{4}$.

Los animales tienen en nuestro sistema jurídico continental, la consideración de cosas en propiedad. La atribución del estatuto de cosas (res) $)^{5}$, referido a los animales, es una creación de la técnica jurídica romana, que, en su momento, integra a las dos principales fuerzas de trabajo de una sociedad eminentemente agrícola (los esclavos y los animales, sobre todo los de tiro y carga) dentro de los elementos más importantes del patrimonio (mancipium) del jefe de un clan familiar (paterfamilias), es decir, del dueño y único titular del conjunto de los bienes con los que una familia desenvolvía su vida y su actividad económica.

En su momento, la inclusión de los animales dentro del sistema jurídico romano, como una categoría específica dentro de los elementos integrantes de la propiedad, significó un cambio muy importante, pues en otras sociedades de la Antigüedad, los animales y los esclavos existían (por supuesto!), pero fuera de la realidad jurídica, es decir, no incluidos dentro de un sistema de Derecho. De ahí que, como es bien sabido, otorgar a los esclavos y a los animales el mismo estatuto jurídico, por mucho que hoy nos parezca rechazable y paradójico, es lo que ha permitido que la situación de los esclavos, en el devenir histórico, mejorara a través de la manumisión y, definitivamente se aboliera. La abolición de la esclavitud no hubiera sido posible de no haber figurado los esclavos como una categoría jurídica. En aplicación de la misma lógica, hoy en día nos planteamos el cambio de estatuto jurídico de los animales, como cosas en propiedad, porque están identificados como una categoría jurídica y éstas admiten cambios, mejoras y supresiones.

Que en una sociedad configurada como la que sumariamente he descrito, los animales (básicamente, los que servían para el transporte, el sustento y el trabajo) ocuparan durante siglos un

1 Ulpian D. 1,1,1,3: lus naturale est, quod natura omnia animalia docuit: nam ius istud non humani generis proprium, sed omnium animalium, quae in terra, quae in mari nascuntur, avium quoque commune est. hinc descendit maris atque feminae coniunctio, quam nos matrimonium appellamus, hinc liberorum procreatio, hinc educatio: videmus etenim cetera quoque animalia, feras etiam istius iuris peritia censeri.

2 OBERGFELL, E.I., Tiere als Mitgeschöpft im Zivilrecht, en Rechtswissenschaft 3 (2016) 388ss.

3 KELCH, T., A Short History of (mostly) Western Animal Law: Part I, Animal Law Review (2012) 1ss.; Part II, Animal Law Review (2013) 1ss.

4 Vid. Entre otros, DIERAUER, U., Tier und Mensch im Denken der Antike (Amsterdam 1977); INGVILD GILHUS, A., Animals, Gods and Humans (London-New York 2006); ALEXANDRIDIS, WILD, WINKLER-HORACEK (ed.), Mensch und Tier in der Antike (Wiesbaden 2008).

5 GIMÉNEZ-CANDELA, T., Derecho Privado Romano (Valencia 1999) 
lugar indiscutido dentro de la propiedad, se justifica principalmente porque la sociedad no cambió sustancialmente de forma y estructura hasta muy recientes siglos, particularmente, a partir de la Revolución Industrial. Por lo tanto, el Derecho, conforme a un panorama social y económico muy semejante al de la Antigüedad clásica, no se preocupó de introducir cambios -ni siquiera de planteárselos-respecto a la relación jurídica con los animales. La cuestión de la propiedad sobre los animales, ha sido pacífica e indiscutida hasta épocas muy recientes ${ }^{6}$.

Todo el legado del Derecho Romano se vertió, de modo prácticamente inalterado, a través de la Codificación napoleónica al mundo contemporáneo. No es de extrañar que el propio Napoleón (“... un nuevo Derecho para un nuevo ciudadano”) insistiera con lucidez -aún en medio de la penuria de sus últimos años de destierro en un islote azotado por el viento-, en que su nombre no aparecería asociado para la posteridad, a los de las grandes batallas con las que se había adueñado de Europa, sino al de la recopilación unificada del Derecho que él encargó llevar a término a ilustres juristas y que aún hoy se conoce como Code civil o Code Napoleon

El Derecho, a través de la Codificación, se ha ocupado de los animales -dentro de la lógica de la pertenencia a las cosas-, en la medida en que aquéllos han cubierto las necesidades más elementales de la vida: como productos, como medios de transporte, como medios para la investigación, como compañía, como parte de los espectáculos dirigidos a divertir al ser humano. Así mismo, el Derecho se ha ocupado de los animales en la medida en que han sido fuente de responsabilidad, en caso de conflictos de intereses, mediando o participando un animal en tal conflicto.

Cuestión aparte, en mi opinión, es la respuesta que el Derecho ha dado al maltrato animal a través del Derecho Penal, pues es misión de un Estado constitucional democrático proveer de sanciones, frente los comportamientos que cuestionan la eficacia de la facultad punitiva que le incumbe ${ }^{8}$. Éste es un mandato, en el que, naturalmente la cuestión de la propiedad sobre los animales juega también un papel ${ }^{9}$, pero el castigo por el maltrato animal se asocia a los comportamientos que la ley determina como ilícitos y en los que el Estado asume una particular misión de vigilancia frente a los más vulnerables ${ }^{10}$.

Sin embargo, el pensamiento crítico sí ha recogido en muchas ocasiones a lo largo de los siglos, la inicial consideración de respeto universal por los animales y el deseo de protegerlos frente a los abusos y agresiones, para suscitar la cuestión de atribuirles una posición jurídica mejor que la de la propiedad sobre ellos. Dicho en otros términos, la Filosofía ${ }^{11}$, la Ética ${ }^{12}$, la Antropología, la Historia, y recientemente la Ciencia del Bienestar Animal, sí se han cuestionado que los animales permanezcan ligados al estatuto de cosas en propiedad y, además, que dicho estatuto justifique, no ya el uso sobre ellos, sino también el abuso sin límites sobre la vida y la integridad física de los animales ${ }^{13}$.

Por lo dicho, queda patente que, a día de hoy, la cuestión del estatuto jurídico de los animales y su eventual cambio, concretamente en el Código civil, ha dejado de ser una cuestión que sólo interesa

6 MUÑOZ MACHADO, S., Los animales y el Derecho (Madrid 1999) 70s.

7 Llamado "Le Code civil des Français", se promulgó el 21 de marzo de 1804 y empezó a conocerse como Code Napoleon desde 1807.

8 RIOS CORBACHO, JM., Comentario en relación al maltrato de animales. LO1/2015 (http://www.derechoanimal.info/images/pdf/CorbachoReforma.pdf; REQUEJO CONDE, MC., El delito de maltrato a los animales tras la reforma del Código Penalpor la ley Orgánica 1/2015 de 30 de marzo (http://www.derechoanimal.info/images/pdf/Requejo.pdf)

9 WOHLERS, W., Tierschutz durch Strafrecht?. Zur Legitimation tierschutzstrafrechtlicher Normen, en Rechtswissenschaft 3 (2016) 426ss.

10 ROXIN, K., Sinn und Grenzen Staatlicher Strafe, JuS (1996) 377, 383n.20: “...im Schmerzempfinden der Tiere, dem sich die Rechtsordnung aus einer Art von kreatürlicher Solidarität annimmt”.

11 REgAn, T., The Case for Animal Rights (University California Press 1983); CAPACETE, F., En recuerdo de Tom Regan(http://www.derechoanimal.info/esp/page/5091/en-recuerdo-de-tom-regan)

12 POLLO, S., Umani e Animali: questioni di Etica (Roma 2016).

13 BOISSEAU-SOWINSKI, L., La désappropiation de l'animal (Presses Universitaires de Limoges 2013). 
y moviliza a los movimientos de defensa de los animales (que también!), para pasar a ser una cuestión que:

-preocupa a la Ciencia y al lenguaje jurídico acerca de los animales como seres sintientes ("sentient beings”)

-preocupa a la sociedad en su conjunto, que ha desarrollado una nueva sensibilidad -preocupa a la organización política del Estado, que asume su responsabilidad frente al Bienestar Animal que es uno de los principios rectores de la UE -preocupa a la economía y a la educación en el respeto a los animales, en todos los niveles de la enseñanza

Que la cuestión animal es una cuestión global, se evidencia con sólo echar una mirada a la evolución del Derecho Animal ${ }^{14}$, una disciplina emergente del Derecho, que se afirma, cada vez más como un instrumento que facilita el "giro" que precisa el Derecho para abrirse a nuevas perspectivas y admisión de nuevas fronteras ${ }^{15}$, que, a mi modo de ver se pueden resumir en:

Descosificación de los animales, Constitucionalización de los animales y Globalización de los animales.

Sobre Descosificación de los animales vengo insistiendo desde mis primeros escritos en tema de Derecho Animal y figura como hilo conductor de todas las investigaciones y proyectos que desde esta web (http://www.derechoanimal.info/esp/page/1434/introduccion) y desde el ICALP se han alentado.

Que el Código civil español reconozca a los animales como "seres vivos dotados de sensibilidad", al igual que han hecho los Códigos civiles de Francia $(2015)^{16}$ y de Portugal (2016) ${ }^{17}$, no sería más que el resultado de una actuación consecuente del Gobierno a quien una reciente petición de reforma, iniciada por el “Observatorio de Justicia y Defensa Animal” y avalada por más de un cuarto de millón de firmas de ciudadanos ${ }^{18}$, ha instado a iniciar los trámites para "promover las reformas legales necesarias para crear una categoría especial en el Código civil distinta a las ya previstas, referida a los animales, donde se les defina como seres vivos dotados de sensibilidad" ${ }^{19}$.

Antes de las reformas llevadas a cabo en Francia y Portugal, la “Descosificación” de los animales se ha perfilado como un movimiento que, con intermitencias, no ha cesado de avanzar desde que en 1988 en Austria se introdujera, en la clasificación de los animales, la afirmación, formulada de forma negativa, de que los animales no son cosas (“nicht-Sachen”) ${ }^{20}$. Esta misma formulación

14 Por todos, FAVRE, D., Animal Law, Welfare, Interests and Rights (New York 2011); How Common Law Equity Concepts can help enhance Animal's Status, en Animals and the Law (Valencia 2015)181ss.

15 PETERS, A., Vom Tierschutzrecht zu Legal Animal Studies: Forschungsdesiderate und -perspectiven, en 3 (2016)332s.

16 Entre sus muchos escritos sobre el tema, vid. esp.: MARGUÉNAUD, JP., L'entrée en vigueur de “l'amendement Glavany”: un grand pas de plus vers la personnalité juridique des animaux, en RSDA 2 (2014) 15ss.; GIMÉNEZ-CANDELA, T., Una nueva Revolución Francesa: la modernización del Code civil (http://www.derechoanimal.info/esp/page/3718/una-nueva-revolucion-francesa-la-modernizacion-del-code-civil

17 ARAUJO, F., A hora dos Direitos dos Animais. O Obstaculo da Apropriaçao (Coimbra 2003) 303ss.; GIMÉNEZ-CANDELA, T., Reforma del Cc. de Portugal: los animales como seres sintientes (http://www.derechoanimal.info/esp/page/4990/reforma-del-cc-de-portugal-los-animales-como-seressintientes)

18 Codina, JI., Unanimidad en el Congreso de los Diputados para instar la reforma del Código civil Español y reconocer a los animales como seres dotados de sensibilidad (http://www.derechoanimal.info/images/pdf/SeresDotadosSensibilidad.pdf

19 Diario de Sesiones del Congreso de los Diputados Pleno y Diputación Permanente, 14.2.2017 (29) $43 \mathrm{ss}$. (http://www.congreso.es/public oficiales/L12/CONG/DS/PL/DSCD-12-PL-29.PDF)

20 ABGB §285a, de 1 de Julio de 1988 (BGBl 179/188; JGS Nr.946/1811):“ § 285a Tiere sind keine Sachen; sie werden durch besondere Gesetze geschützt. Die für Sachen geltenden Vorschriften sind auf Tiere nur insoweit anzuwenden, als keine abweichenden Regelungen bestehen. (=Animals are not things; they are protected by special statutes. Provisions applicable to things only apply to animals to the extent there are no different provisions). 
(“nicht-Sachen”) de que los animales son “no-cosas”, es la que se siguió en Alemania, Suiza, Liechtenstein en los siguientes años ${ }^{21}$, con diferentes resultados en cada uno de estos países.

Cabe decir, para finalizar, que aunque no se haya logrado -tampoco se pretendía- que los animales sean equiparados a los seres humanos en cuanto a prerrogativas y consecución de "derechos subjetivos”, sí cabe destacar que la modificación del estatuto jurídico de los animales está reforzando en todos estos países el ámbito de aplicación jurídica de la condición de los animales como lo que son: seres sintientes.

Sobre los concretos significados y extensión de esta expresión, procedente de la Ciencia del Bienestar Animal y de su integración en el ámbito jurídico, me extenderé muy pronto en la parte II de este artículo sobre Descosificación de los animales.

\section{LA EDITORA}

Teresa Giménez-Candela

Catedrática de Derecho Romano

Directora del Master en Derecho Animal y Sociedad

Directora del ICALP

Universitat Autònoma de Barcelona

Sígueme en Facebook: https://www.facebook.com/editora.da

21 Alemania: BGB §90ª, de 20 de Agosto de 1990, BGBl I, p.1762); Suiza: ZGB, modificación de 4 de Octubre de 2002 (AS 2003, 463; BBl 2002 4164, 5806); Liechtenstein: Art. 20a Liechtensteinisches Sachenrecht, de 14 de Mayo de 2003, sobre el cambio del Derecho de Propiedad, LR 214.0, 2003 N. 155) 